\title{
Dissolution Study of Active Pharmaceutical Ingredients Using the Flow Through Apparatus Usp 4
}

\author{
E. Beyssac and J. Lavigne \\ ERT CIDAM, Biopharmaceutics Department, Faculty of Pharmacy, PO Box 38, 63000 Clermont-Ferrand, France
}

Abstract

The flow through system has been employed for many years in the testing of different dosage forms such as tablets and capsules. The flow through cell is the method of choice for extended release and poorly soluble products. Thanks to the specific powder cell it is possible to characterize a drug substance with respect to its rate of dissolution.

The aim of this work was to compare the biopharmaceutical properties of different batches of a drug substance using the dissolution rate determined using the flow through apparatus.

The apparatus consists of a reservoir of dissolution medium, a pump that forces the dissolution medium upwards through the flow through cell and a cell specifically designed for powders, mounted vertically with a filter system preventing escape of undissolved particles. In the flow through method the test sample is located in a small-volume cell through which solvent passes at a temperature of $37^{\circ} \mathrm{C}$.

Five batches of theophylline with a mean diameter of $128 \mu \mathrm{m}$ to $673 \mu \mathrm{m}$ and two batches of acetylsalicylic acid, either fine particles or needles, were studied. The experiment was conducted using six cells in an open system.

Through the results obtained, the relationship between particle size distribution and dissolution rate has been verified. The rate of dissolution is faster for drug with low particle size and a higher surface area. The experimental parameters such as flow rate have been studied and optimized.

The overall results demonstrate that it is possible to characterize the biopharmaceutical qualities of active pharmaceutical ingredients using the flow through cell. The method is reliable, reproducible and discriminating. It can easily be used to compare drugs with different particle size distributions.

\section{Introduction}

D issolution is a critical parameter of pharmaceutical dosage forms. It is well recognized that in vitro dissolution testing, whether in development or in circulation, is relied upon to screen formulations during development and to ensure batch-to-batch quality control. In the USA and in Europe, more than 30 years of research have been devoted to characterizing the biopharmaceutical properties of drug products. Several guidelines have been published and all pharmacopoeias include a description of dissolution testing $(1,2,3,4)$.

During drug development, in vitro dissolution testing is an important tool in the evaluation of the best formulation and also in the understanding of possible risks related to specific gastrointestinal environment, dose dumping, food effects on bioavailability and interaction with other drugs. Today, dissolution studies are the most frequently used tools in the development, characterization and utilization processes of controlled release formulations.

Dissolution is the process by which a solid solute with relatively low solubility enters into a solution in the presence of solvent (5). Dissolution rate may be defined as the amount of active ingredient in a solid dosage form dissolved in unit time under standardized conditions of liquid/solid interface, temperature, and media composition.

A discriminative dissolution method has to be developed to exhibit different results when the manufacture or composition of a product changes. The dissolution method should be sensitive to variations that can have an impact on the in vivo performance of the dosage form. Among the different variations such as process, equipment, or materials, the characterization of the active pharmaceutical ingredient (API) is of prime importance. The crystal form of the API, its particle size distribution and its surface area are critical. Examining the dissolution rate can help consolidate this valuable information.

Among the different in vitro systems available for API testing, the flow through system (USP Method 4) offers the best characteristics. It has been employed for many years in the testing of different dosage forms such as tablets and capsules. It is the method of choice for extended release and poorly soluble products. Using the specific powder cell, it is possible to characterize a drug substance with respect to its rate of dissolution.

The aim of this work was to compare and characterize the biopharmaceutical properties of different batches of phar-

\section{Table 1: Mean particle size of theophylline batches}

\begin{tabular}{|lc|}
\hline Product & Mean diameter $(\mu \mathrm{m})$ \\
\hline Theophylline monohydrated & 128 \\
Theophylline crystallized & 135 \\
Theophylline fine powder & 120 \\
\hline Theophylline granular SR & 675 \\
Theophylline granular SR8 & 625 \\
\hline
\end{tabular}


macopoeial drug substances by performing a dissolution test with the flow through apparatus.

\section{Materials and methods \\ Products}

\section{Theophylline}

Three batches of different theophylline powders with close particle size distribution and two batches of granular theophylline available in the market under different defined particle size distribution were studied. The mean particle diameters of the batches studied are listed in table 1.

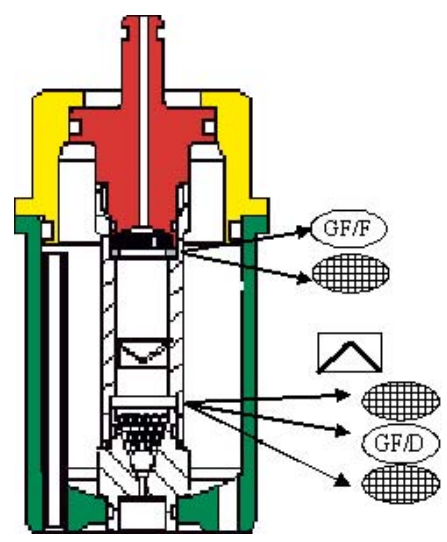

Figure 1. The complete powder cell

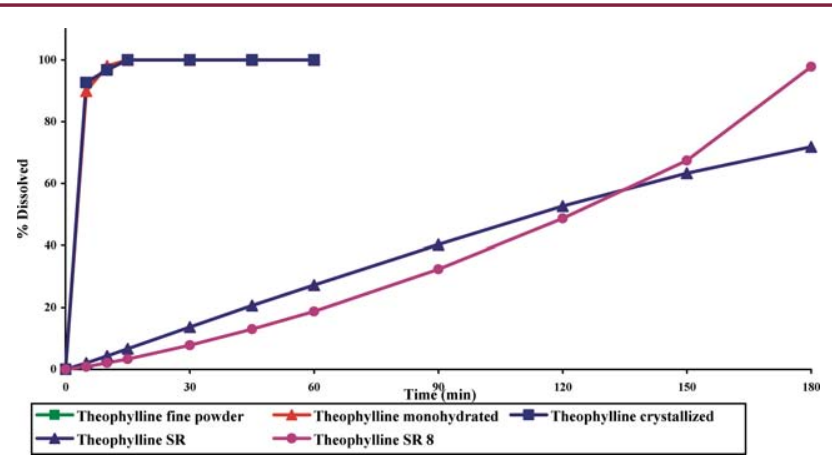

Figure 2. Dissolution study of theophylline batches (flow rate $30 \mathrm{~mL} / \mathrm{min}$, amount of drug $100 \mathrm{mg}$ )

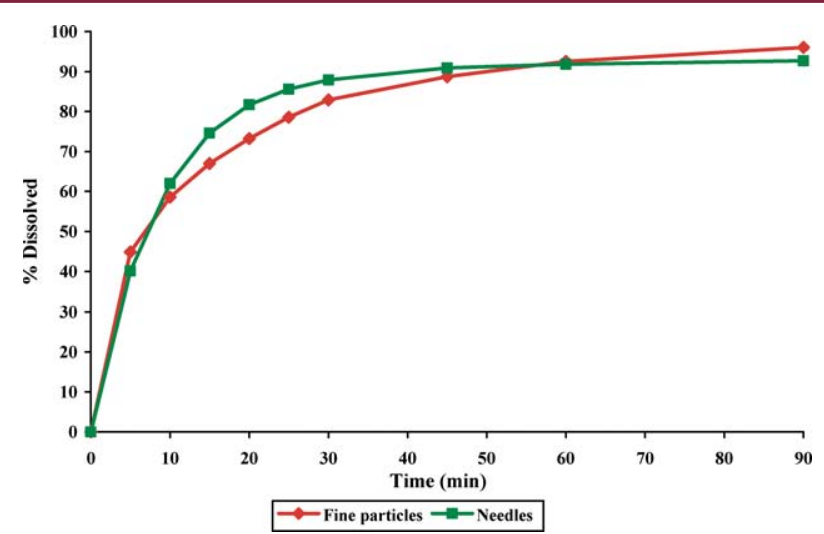

Figure 3. Dissolution study of acetylsalicylic acid (flow rate $30 \mathrm{~mL} / \mathrm{min}$, amount of drug $50 \mathrm{mg}$ )

\section{Acetylsalicylic acid}

Two batches of acetylsalicylic acid, either fine particles or needles, were investigated.

\section{In vitro dissolution test}

A flow through cell dissolution apparatus with six cells, Dissolution tester Dissotest CE-6, Sotax AG, Basel, was used in all experiments. During testing, the dissolution medium was pumped through each cell with a piston pump CY7, Sotax AG, Basel. Dissolution flow through cells for powder with a diameter of $12 \mathrm{~mm}$, Sotax AG, Basel, were employed to study the different API.

One glass bead of 5-mm diameter was positioned in the apex of the flow-through cell and the lower conical part of the cell was filled with glass beads of about 1-mm diameter. Two sieves separated by a glass microfiber filter (GF/D Whatman) and the defined amount of powder to be studied were respectively placed on the top of the layer of beads. The cell was closed with the prepared insert and the filter assembly consisting of one sieve and a glass microfiber filter (GF/F Whatman). The complete powder cell is presented in Figure 1.

\section{Experimental conditions}

Each experiment was conducted on six independent cells in an open system. The dissolution media were warmed up to $37^{\circ} \mathrm{C}$. The dissolution medium, prepared according to USP 2, was $\mathrm{pH} 1.2$ for acetylsalicylic acid and phosphate buffer $\mathrm{pH} 7.2$ for theophylline. For each interval, samples were collected in volumetric flasks at the following times:5, $10,15,45,60,90,120,150$, and 180 minutes according to the drug studied. The concentration of each sample was determined using UV/VIS spectrometer (UV-160 A Shimadzu) at $296 \mathrm{~nm}$ for acetylsalicylic acid and at $272 \mathrm{~nm}$ for the theophylline without further dilution.

\section{Results and discussion Influence of particle size distribution \\ Theophylline}

The results obtained with the three batches of theophylline powders and the two batches of granular theophylline are presented in Figure 2.

\section{Acetylsalicylic acid}

The results obtained with the two batches of acetylsalicylic acid powders are presented in Figure 3.

Dissolution studies when applied to powders enable the optimization of formulation variables, including particle size. Through the results obtained, the relation between particle size distribution and dissolution rate has been verified. The rate of dissolution is faster for drug with low particle size and higher surface area.

\section{Influence of flow rate}

Studied were performed on theophylline (fine powder) and theophylline (granular) using the following flow rates: $15 \mathrm{~mL} / \mathrm{min}, 30 \mathrm{~mL} / \mathrm{min}$ and $45 \mathrm{~mL} / \mathrm{min}$. The results are presented in Figures 4 and 5.

With a $45 \mathrm{~mL} / \mathrm{min}$ flow rate, the dissolution of theophylline 
granular SR is significantly increased compared to $15 \mathrm{~mL} / \mathrm{min}$ and $30 \mathrm{~mL} / \mathrm{min}$. With a $45 \mathrm{~mL} / \mathrm{min}$ flow rate, there is practically no change in the dissolution of theophylline fine powder compared to the results obtained with a $30 \mathrm{~mL} / \mathrm{min}$ flow rate. At $15 \mathrm{~mL} / \mathrm{min}$, the decrease in dissolution rate is significant.

The status of the solid/liquid interface is the key dissolution parameter: it is the point at which fresh solvent comes into contact with the surface of the solid to be dissolved. An in vitro system should ideally maintain sink condition, and the dissolving solid should be bathed in fresh solvent. In order to insure experiment reproducibility, the rate at which fresh solvent contacts a surface area should be kept constant. The flow should be laminar and devoid of turbulence. In the flow through method, the test sample is located in a small-volume cell through which solvent passes at a temperature of $37^{\circ} \mathrm{C}$. In an open system, fresh dissolution medium is continuously supplied to the sample over the testing time.

The flow rate represents the hydrodynamic agitation of the dissolution medium on the powder. The flow rate modifies the status of the solid/liquid interface. The results showed differences in the in vitro release profiles. Increasing the flow rate increased the dissolution rate of powder. According to the particle size and particle shape of the powders, the flow rate between 5 and $50 \mathrm{~mL} / \mathrm{min}$ must be optimized in order to give the best reproducibility and to maintain the discriminative power of the dissolution method.

The determination of experimental conditions is important in order to obtain reliable results. The following parameters have to be fixed and studied:medium flow rate, filter type (it must retain the undissolved particles without interfering in the experiment by increasing cell pressure) and the amount of drug (a function of the wettability of the compound).

\section{Conclusion}

The biopharmaceutical properties such as particle size distribution, specific surface area, and rate of dissolution can characterize a drug and should be considered early in the development of a drug product. The flow through cell can be used to determine the apparent dissolution rate without any modification of the drug (no compaction or dilution with inert excipient). The experimental results demonstrate the relationship between particle size distribution and dissolution rate.

Biological studies have shown that the gastrointestinal tract acts as a natural sink: the drug is absorbed as soon as it dissolves. Thus, in vivo there is no concentration build-up at the absorption site; drug concentration in the surrounding fluid remains very low and dissolution occurs under what is termed "sink condition."The advantage of the flow through cell is its ability to permit a suitable continuous flow through an open circuit. The contact point is continuously renewed. The use of large dissolution volume allows the sink condition to be maintained through out the experiment whatever the drug solubility. The method is reliable, reproducible and discriminative.

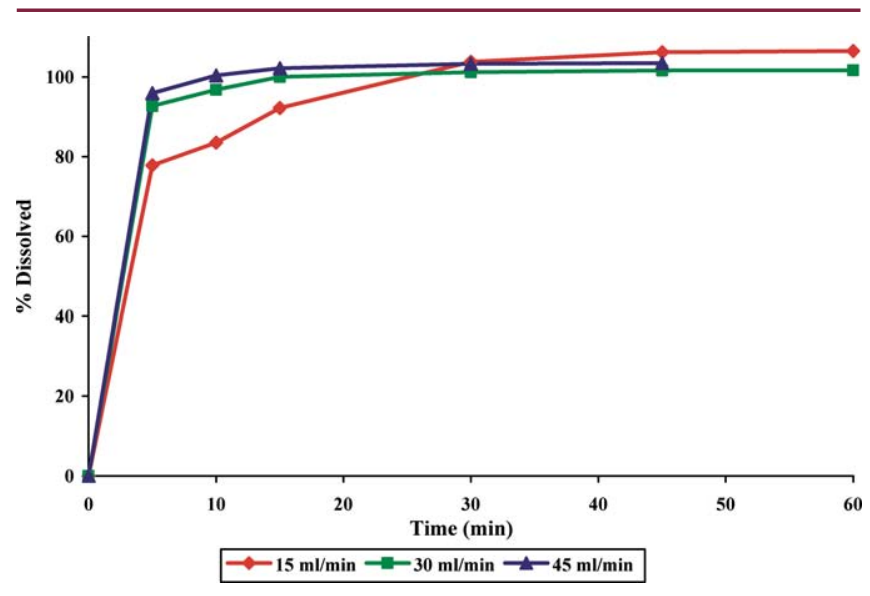

Figure 4. Dissolution study of theophylline fine powder with different flow rates (Batch studied: fine powder, amount of drug $200 \mathrm{mg}$ )

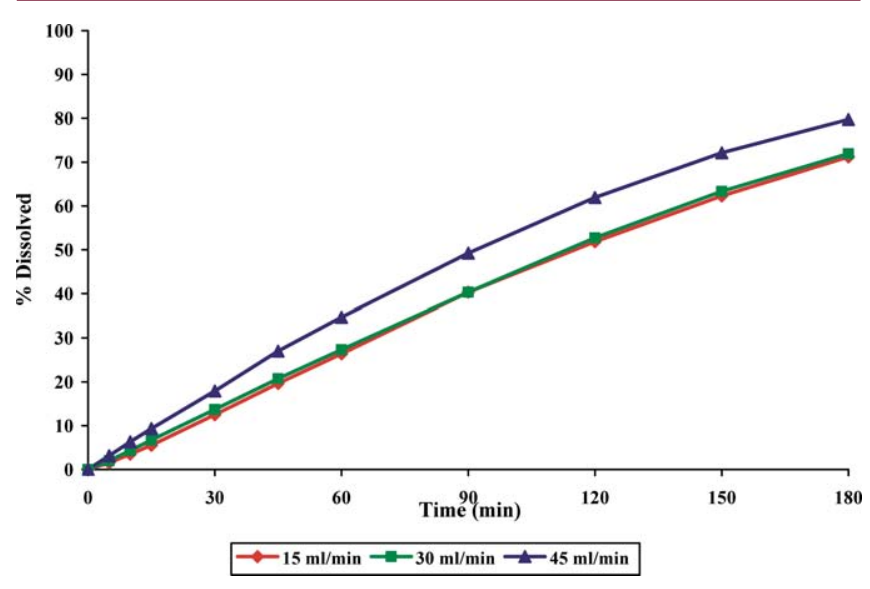

Figure 5. Dissolution study of theophylline granular SR with different flow rates (Batch studied: Granular SR, amount of drug $200 \mathrm{mg}$ )

This method can be applied to select a drug in the preformulation stage, to compare drugs with different particle size distributions and to maintain API quality control.

\section{References}

1. Guidance for Industry: Dissolution Testing of Immediate Release Solid Oral Dosage Forms, U.S. Department of Health and Human Services, Food and Drug Administration, Center for Drug Evaluation and Research (CDER), August 1997

2. Guidance for Industry: Extended Release Oral Dosage Forms: Development, Evaluation, and Application of In Vitro/In Vivo Correlations, U.S. Department of Health and Human Services, Food and Drug Administration, Center for Drug Evaluation and Research (CDER), September 1997

3. United States Pharmacopeia and National Formulary, United States Pharmacopeia Convention Inc., Rockville, MD, USA, 26 ${ }^{\text {th }}$ Edition, 2003

4. European Pharmacopeia, Council of Europe, Strasbourg, France, 2001

5. Amiji, M.A., Sandmann B.J., Applied physical pharmacy, McGraw-Hill Companies; USA, 2003 